\title{
PENGEMBANGAN WEB PEMBELAJARAN MATEMATIKA MATERI ARITMATIKA SOSIAL
}

\author{
Mukhammad Danisworo', Yus Mochamad Cholily², Alfiani Athma Putri \\ Rosyadi $^{3}$ \\ 1,2 Pendidikan Matematika, Universitas Muhammadiyah Malang
}

danisworom@yahoo.com¹, yus@umm.ac.id², athmaputri@gmail.com³

\begin{abstract}
Abstrak
Penelitian ini bertujuan untuk mengembangkan web pembelajaran matematika materi aritmatika sosial dan melihat respon siswa terhadap web pembelajaran matematika materi aritmatika sosial. Metode penelitian yang digunakan adalah Research and Development (R\&D) yang dimulai dari menentukan potensi masalah, pengumpulan data, desain produk, validasi desain, revisi desain, uji coba produk, dan revisi produk. Subjek pada penelitian ini adalah siswa kelas VII di MTs Muhammadiyah 1 Malang dan dipilih 6 siswa dengan kategori 2 tinggi, 2 sedang, dan 2 rendah dari hasil ulangan aritmatika sosial yang sudah dilakukan. Hasil penelitian menunjukkan bahwa: 1) web pembelajaran yang sudah dikembangkan mendapatkan skor 3,73 dari validasi ahli media dan validasi ahli materi mendapatkan skor 3,55 yang berarti web pembelajaran valid; 2) respon siswa terhadap web pembelajaran memperoleh skor 3,65 (tinggi).
\end{abstract}

Kata kunci: pengembangan, web pembelajaran matematika, aritmatika sosial

\begin{abstract}
This study aims to develop a mathematics learning for social arithmetic material and see student responses to the mathematics learning web for social arithmetic material. The research method used is and Development (R \& D) which starts from determining potential problems, data collection, product design, design validation, design revisions, product trials, and product revisions. The subjects in this study were VII grade students at MTs Muhammadiyah 1 Malang and 6 selected students with categories 2 high, 2 medium, and 2 low from the results of social arithmetic tests that had been done. The results showed that: 1 ) the learning web that had been developed gets a score of 3.55 which means the learning web is valid; 2) student responses to the learning web gained a score 3.65 (high).
\end{abstract}

Keywords: development, mathematics learning web, social arithmetic

\section{PENDAHULUAN}

Internet bukan hal yang asing lagi di zaman modern ini, karena hampir seluruh kalangan mendengar tentang internet. Berkembangnya 
internet di dapat membuat kehidupan menjadi lebih mudah. Internet memiliki berbagai macam layanan, salah satu layanan yang paling sering digunakan adalah web. Web adalah layanan internet yang didalamnya terdapat berbagai macam informasi yang bisa diakses oleh semua orang dengan menggunakan bantuan aplikasi browser (Utama, 2011). Web dapat digunakan seseorang sebagai media pembelajaran.

Media pembelajaran merupakan alat peraga yang digunakan guru untuk membantu dalam pembelajaran agar lebih mudah dalam memahamkan konsep dan materi kepada peserta didik (Wati, 2016). Sedangkan Johar (2014) mengatakan bahwa media pembelajaran web merupakan sarana penyampaian materi dari pengajar ke peserta didik dengan menggunakan fasilitas internet sehingga dapat diakses dari manapun dan kapanpun. Pemanfaatan web diharapkan dapat membiasakan peserta didik aktif belajar sehingga pembelajaran lebih bersifat student centered (Rahman, 2014). Raharjo (2007) juga menyatakan bahwa penerapaan pembelajaran berbasis web dapat meningkatkan pencapaian kompetensi mahasiswa. Selain itu, penggunaan web sebagai media pembelajaran menciptakan proses pembelajaran lebih menarik dan peserta didik lebih mandiri dalam mencari sumber informasi yang berhubungan dengan materi yang diajarkan guru (Jas, Rosha, \& ZA, 2012).

Sistem informasi berbasis website dapat memenuhi kebutuhan sekolah sebagai media atau sarana penyampaian informasi (Riyadi, 2012). Menurut Wati (2016) guru dapat memanfaatkan fasilitas teknologi informasi yang sudah disediakan sekolah untuk membuat dan mengembangkan web sebagai media pembelajaran. Berdasarkan hasil penelitian diketahui bahwa media pembelajaran berbasis web yang telah dikembangkan mampu memotivasi siswa untuk belajar matematika. Media pembelajaran berbasis web yang telah dibuat masih terbatas pada materi barisan dan deret. Jumlah butir soal dalam latihan soal masih terbatas sehingga perlu adanya pengembangan agar jumlah butir soal dalam latihan soal lebih banyak dari sebelumnya (Setyadi \& Qohar, 2017). Menurut Own dalam Rhamandica (2016), pembelajaran berbasis web dapat membantu mahasiswa dalam mengonstruksi konsep materi.

Pada penelitian ini, materi yang akan dikembangkan adalah aritmatika sosial. Aminah (2018) mengatakan bahwa salah satu cabang matematika yang sering digunakan dalam kehidupan sehari-hari adalah aritmatika sosial. Selain itu, alasan dipilihnya materi aritmatika sosial karena berdasarkan hasil wawancara terhadap guru matematika, diketahui bahwa kegiatan pembelajaran pada materi aritmatika sosial hanya menggunakan papan tulis sebagai media pembelajaran. Sehingga perlu dikembangkan pembelajaran berbasis web pada materi aritmatika sosial. Tujuan penelitian ini yaitu dapat 
mengembangkan website sebagai media pembelajaran matematika pada materi aritmatika sosial.

\section{METODE PENELITIAN}

Penelitian ini menggunakan metode penelitian Research and Development milik Sugiyono dan hanya diambil 7 tahap dari 10 tahapan yang ada. Research and Development adalah metode penelitian yang digunakan untuk menghasilkan atau mengembangkan produk agar menjadi lebih baik dan produk tersebut harus diuji keefektifannya (Sugiyono, 2016).

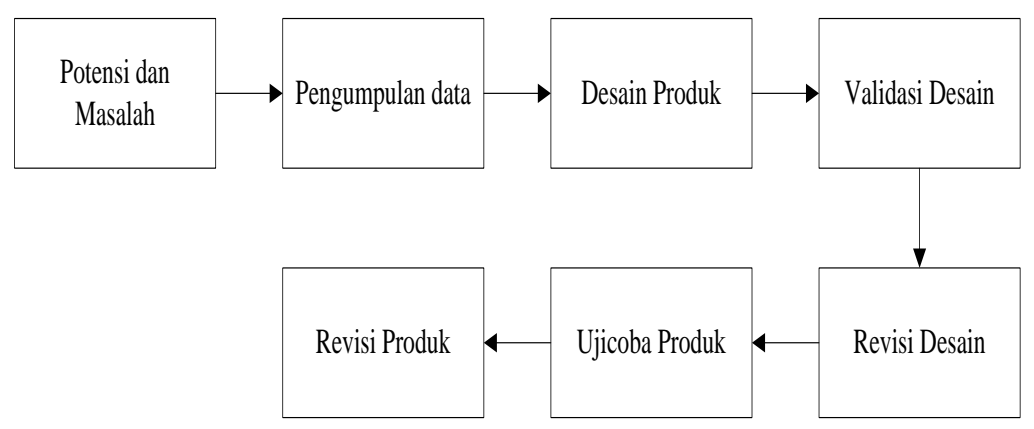

\section{Gambar 1 Tahapan Penggunaan Metode Research and Development (R\&D)}

Potensi dan masalah diperoleh dari hasil wawancara terhadap guru matematika bahwa kegiatan pembelajaran di MTs Muhammadiyah 1 Malang pada materi aritmatika sosial hanya menggunakan papan tulis sebagai media pembelajaran. Pengumpulan data dilakukan dengan cara mencari buku matematika kurikulum 2013 yang memuat materi aritmatika sosial untuk dijadikan acuan. Mencari aplikasi apa saja yang berfungsi dalam pengembangan web pembelajaran matematika seperti XAMPP, Notepad++ dan kemudian menginstall aplikasi tersebut.

Desain produk, tahap desain produk yang pertama kali dilakukan yaitu membuat desain tampilan halaman utama web. Membuat rancangan tampilan awal sebuah web harus sesuai dengan siswa SMP agar memudahkan dalam mengoperasikan web tersebut, konsep dan desain dibuat menarik tetapi tetap simpel dan tidak mencolok, agar siswa dapat belajar dengan baik. Validasi desain, tahap validasi desain merupakan tahap yang penting karena pembuat web dapat melihat apakah web pembelajaran sudah valid atau belum. Validator web pembelajaran ini terdiri dari 2 validator ahli media dan 2 validator ahli materi. Validator ahli media yaitu dosen pendidikan matematika Universitas Muhammadiyah Malang. Validator ahli materi yaitu dosen pendidikan matematika Universitas Muhammadiyah Malang dan guru matematika MTs. Muhammadiyah 1 Malang. Revisi desain, hasil validasi web pembelajaran matematika materi aritmatika sosial 
dikatakan valid tetapi harus di perbaiki sesuai komentar dan saran dari ahli media dan ahli materi. Ujicoba produk, uji coba dilaksanakan di MTs. Muhammadiyah 1 Malang dengan jumlah 6 siswa kelas VII- B yang dipilih berdasarkan hasil ulangan materi aritmatika sosial yang sudah dilaksanakan dan dipilih 2 tertinggi, 2 sedang, 2 terendah.

Data yang dibutuhkan untuk pengembangan web pembelajaran matematika materi aritmatika sosial adalah data validitas dari para ahli media, ahli materi dan hasil respons siswa terhadapa web pembelajaran yang sudah dikembangkan. Sumber data yang dibutuhkan untuk pengembangan web pembelajaran ini adalah: a) Ahli Media sebagai validator media pembelajaran. b) Ahli Materi Pembelajaran Matematika sebagai validator materi pembelajaran. c) Siswa merupakan sumber data untuk mengetahui respons siswa terhadap web pembelajaran yang telah dikembangkan.

Penelitian ini menggunakan instrumen angket sebagai alat untuk mendapatkan informasi dari validator dan siswa. Lembar validasi diberikan kepada ahli media dan ahli materi yang dilakukan untuk mengetahui tingkat validitas web pembelajaran. Siswa akan diberikan angket untuk mengetahui respons siswa terhadap web pembelajaran matematika materi aritmatika sosial, dengan begitu bisa diketahui apakah media pembelajaran berbasis web dapat memotivasi siswa dalam belajar dan dapat memahamkan konsep materi aritmatika kepada siswa atau tidak.

Menentukan kategori kevalidan sebuah media pembelajaran berbasis web yaitu dengan melihat rata-rata total dari semua validator (VT) dengan kategori yang ditetapkan sebagai berikut.

Tabel 1 Kategori Kevalidan Media Pembelajaran Berdasarkan Validator
\begin{tabular}{cc} 
Rata-rata Total & Kategori \\
\hline $3^{<} \mathrm{VT}^{\leq}{ }_{4}$ & Valid \\
\hline $2^{<} \mathrm{VT}_{3} s_{3}$ & Kurang Valid \\
\hline $1^{<} \mathrm{VT}^{\leq}{ }_{2}$ & Tidak Valid \\
\hline
\end{tabular}

Jika hasil validasi menunjukkan tidak valid, maka perlu dilakukan revisi media pembelajaran tersebut. Analisis data pada penelitian ini menggunakan skala Likert untuk mengetahui respons siswa terhadap web pembelajaran matematika yang telah dibuat apakah layak atau tidak sebagai sumber belajar selain buku. Menentukan kategori kevalidan suatu media pembelajaran berbasis web berdasarkan respons siswa melalui instrumen angket dengan melihat rata-rata total dari semua siswa (ST) dengan kategori yang ditetapkan sebagai berikut. 
Tabel 2 Kategori Kevalidan Media Pembelajaran Berdasarkan Respon Siswa

\begin{tabular}{cc}
\hline Rata-rata Total & Kategori \\
\hline $3^{<} \mathrm{ST} \leq 4$ & Tinggi \\
\hline $2^{<} \mathrm{ST}_{3} \leq_{3}$ & Sedang \\
\hline $1^{<} \mathrm{ST} \leq{ }_{2}$ & Rendah \\
\hline
\end{tabular}

(Sumber: Sudijono, 2010)

\section{HASIL DAN PEMBAHASAN}

Pembuatan web pembalajaran ini, ada beberapa tahapan yang dilakukan yaitu mencari potensi dan masalah berdasarkan wawancara terhadap guru MTs. Muhammadiyah 1 Malang karena masih belum tahunya media pembelajaran yang sesuai untuk diterapkan pada materi aritmatika sosial. Setelah mengetahui potensi dan masalah selanjutnya dibuat desain produk sesuai dengan materi. Desain yang sudah selesai dan kemudian di kembangkan dalam bentuk produk perlu melakukan validasi yang divalidasi oleh para ahli media dan ahli materi. Hasil dari validasi ahli media dan materi adalah valid, sehingga produk dapat diujicobakan kepada siswa.

Komentar dan saran dari siswa dapat dijadikan pertimbangan untuk revisi produk. 1) Dapat mendukung program Mentri Pendidikan dalam penggunaan Internet di lingkungan sekolah 2) Dapat mendukung atau sebagai pelengkap dalam pembelajaran. 3) Pembelajaran yang dapat dilakukan dari manapun dan kapan pun (time and place flexibility). 4) Dapat bertambahnya interaksi dalam pembelajaran antara guru dan peserta didik. 5) Dapat mengatasi keterbatasanya ruang dan waktu dalam kegiatan pembalajaran. Berdasarkan penjabaran tersebut didapatkan bahwa pengembangan web pembelajaran yang telah dikembangkan dan diterapkan pada MTs. Muhammadiyah 1 Malang layak untuk dipergunakan dalam proses pembelajara dikelas berdasarkan hasil dari uji validasi media, materi dan hasil dari angket respon siswa.

Penelitian lain yang terkait dengan permasalahan pengembangan web pembelajaran adalah penelitian (Setyadi \& Qohar, 2017). Secara keseluruhan penilaian dari ahli media pada penelitian (Setyadi \& Qohar, 2017) adalah 3,1 sedangkan pada media yang dikembangkan oleh peneliti adalah 3,73 . Untuk penilaian ahli materi secara umum dari penelitian (Setyadi \& Qohar, 2017) adalah 3,1 sedangkan pada media yang dikembangkan oleh peneliti adalah sebesar 3,55. Web pembelajaran oleh (Setyadi \& Qohar, 2017) merupakan web pembelajaran yang dikembangkan menggunakan template prezi dan geogebra sedangkan peneliti mengembangkan web menggunakan bahasa pemrograman PHP, JavaScript dibantu HTML dan CSS.

Uji coba penerapan web pembelajaran dilakukan pada siswa kelas VII MTs Muhammadiyah 1 Malang, Uji coba dilakukan selama 2 jam pelajaran di 
kelas dengan jumlah 6 siswa yaitu masing-masing 2 siswa kategori tinggi, sedang, dan rendah. Berdasarkan penilaian oleh 6 siswa diperoleh skor ratarata total 3,65 dari skor maksimal 4 yang berarti respon siswa tinggi terhadap web pembelajaran matematika materi aritmatika sosial. Revisi produk yang terakhir dilakukan berdasarkan hasil ujicoba produk yang sudah dilakukan di MTs Muhammadiyah 1 Malang. Berdasarkan saran dan komentar siswa maka warna pada tombol menu bar sudah diperbaiki dengan memberikan warna merah pada tombol menu bar agar siswa dapat dengan mudah untuk melihat menu bar yang ada. Revisi tersebut sangat membantu agar web pembelajaran matematika pada materi matematika aritmatika sosial menjadi lebih baik lagi.

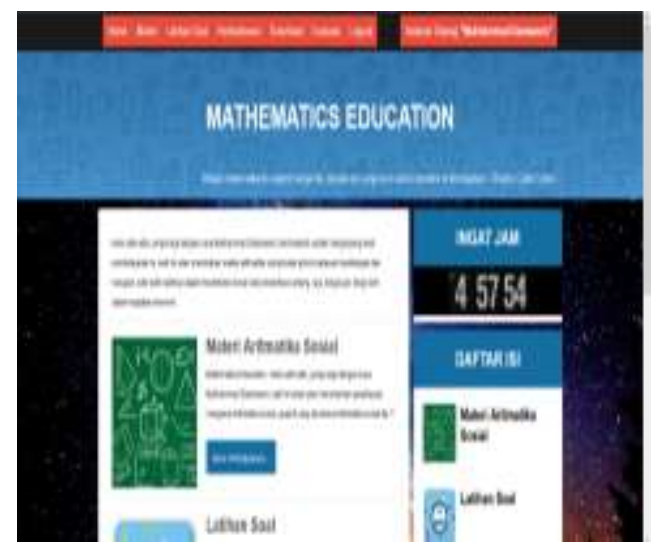

Gambar 2 Hasil Revisi Berdasarkan Respon dan Komentar Siswa

\section{KESIMPULAN DAN SARAN}

Pembuatan web pembelajaran ini, ada beberapa tahapan yang dilakukan yaitu mencari potensi dan masalah berdasarkan hasil wawancara terhadap guru di MTs. Muhammadiyah 1 Malang karena masih belum tahunya media pembelajaran yang sesuai untuk materi aritmatika sosial. Setelah mengetahui potensi dan masalah selanjutnya dibuat desain produk sesuai dengan materi. Desain yang sudah selesai dan kemudian di kembangkan dalam bentuk produk perlu melakukan validasi yang divalidasi oleh ahli media dan ahli materi. Validasi media dan materi yang didapatkan adalah valid, sehingga dapat diuji coba produk kepada siswa. Komentar dan saran dari siswa dapat dijadikan pertimbangan untuk revisi produk.

Berdasarkan penjabaran tersebut didapatkan bahwa web pembelajaran yang telah dikembangkan dan diterapkan pada MTs. Muhammadiyah 1 Malang layak untuk dipergunakan dalam pembelajaran berdasarkan hasil dari uji validasi media, materi dan hasil dari angket respon siswa. Berdasarkan penilaian oleh 6 siswa diperoleh skor rata-rata total 3,65 
dari skor maksimal 4 yang berarti respon siswa tinggi terhadap web pembelajaran matematika pada materi aritmatika sosial. Web pembelajaran matematika yang sudah dibuat juga sudah diperbaiki sesuai dengan komentar dan saran 6 siswa agar web pembelajaran matematika materi aritmatika sosial ini dapat menjadi lebih baik lagi.

Berdasarkan hasil penelitian, dapat diberikan saran terkait pengembangan untuk pembelajaran. Saran yang dapat dikemukakan yaitu sebaiknya pengajar mengembangkan web pembelajaran untuk berbagai materi pelajaran dengan memperhatikan potensi dan masalah dalam pembelajaran.

\section{DAFTAR PUSTAKA}

Aminah, Siti dan Nok I.Y. (2018). Kajian Aitmatika Sosial dalam Perhitungan Ilmu Faraidh (Ilmu Waris) dalam Q.S An Nisa. Jurnal Prismatika, 1 (1).

Jas, I., Rosha, M., \& ZA, N. (2012). Penggunaan Media Pembelajaran Berbasis Website Dalam Pembelajaran Matematika. Jurnal Pendidikan Matematika, 1(1), 1-5.

Johar, Asahar, Eko Risdianto, \& Desty A.F.I. (2014). Perancangan dan Implementasi Media Pembelajaran Berbasis Web pada Bidang Studi Bahasa Inggris di Kelas VII SMP Negeri I Kota Bengkulu dengan Menggunakan PHP dan MYSQL. Jurnal Rekursif, 2 (1).

Raharjo, N. E. (2007). Implementasi Web Based Learning untuk Meningkatkan Pencapaian Kompetensi Mahasiswa Bidang Komputer. Jurnal PTK Fakultas Teknik UNESA, 3 (5).

Rahman, Syaiful, Wahid Munawar, \& Ega T. Berman. (2014). Pemanfaatan Media Pembelajaran Berbasis Website pada Proses Pembelajaran Produktif di SMK. Journal of Mechanical Engineering Education, 1 (1).

Rhamandica, Chintia, Surjani W., \& Munzil Arief. (2016). Pengaruh Pembelajaran Berbasis Web terhadap Hasil Belajar Mahasiswa Jurusan Kimia pada Materi Kimia Inti dengan Kemampuan Self Regulated Learning berbeda. Jurnal Pendidikan, 1 (10).

Riyadi, A.S., Eko Retnandi, \& Asep Deddy. (2012). Perancangan Sistem Informasi Berbasis Website Subsistem Guru di Sekolah Pesantren Persatuan Islam 99 Rancabango. Jurnal Algoritma, 9 (40).

Setyadi, D., \& Qohar, A. (2017). Pengembangan Media Pembelajaran Matematika Berbasis Web pada Materi Barisan dan Deret. UNNES JOURNALS, 8(1), 1-7.

Sudijono, Anas. (2010). Pengantar Statistik Pendidikan. Jakarta: Rajawali Press. 
Mukhammad Danisworo, Yus Mochamad Cholily, Alfiani Athma Putri Rosyadi

Pengembangan Web Pembelajaran Matematika Materi Aritmatika Sosial

Sugiyono. (2016). Metode Penelitian Kuantitatif, Kualitatif dan $R$ \& $D$. Bandung: Alfabeta.

Utama, Y. (2011). Sistem Informasi Berbasis Web Jurusan Sistem Informasi Fakultas Ilmu Komputer Universitas Sriwijaya. Jurnal Sistem Informasi (JSI), 3(2), 359-370.

Wati, E. R. (2016). Ragam Media Pembelajaran. (A. Jarot, Ed.). Jakarta: Kata Pena. 